\title{
Erratum: Localization and temporal regulation of tissue inhibitors of metalloproteinases 3 and 4 in bovine preovulatory follicles
}

Qinglei Li, Leanne J Bakke, J Richard Pursley and George W Smith

Figure 2 was printed in black and white in error. This is the correct, colour version.
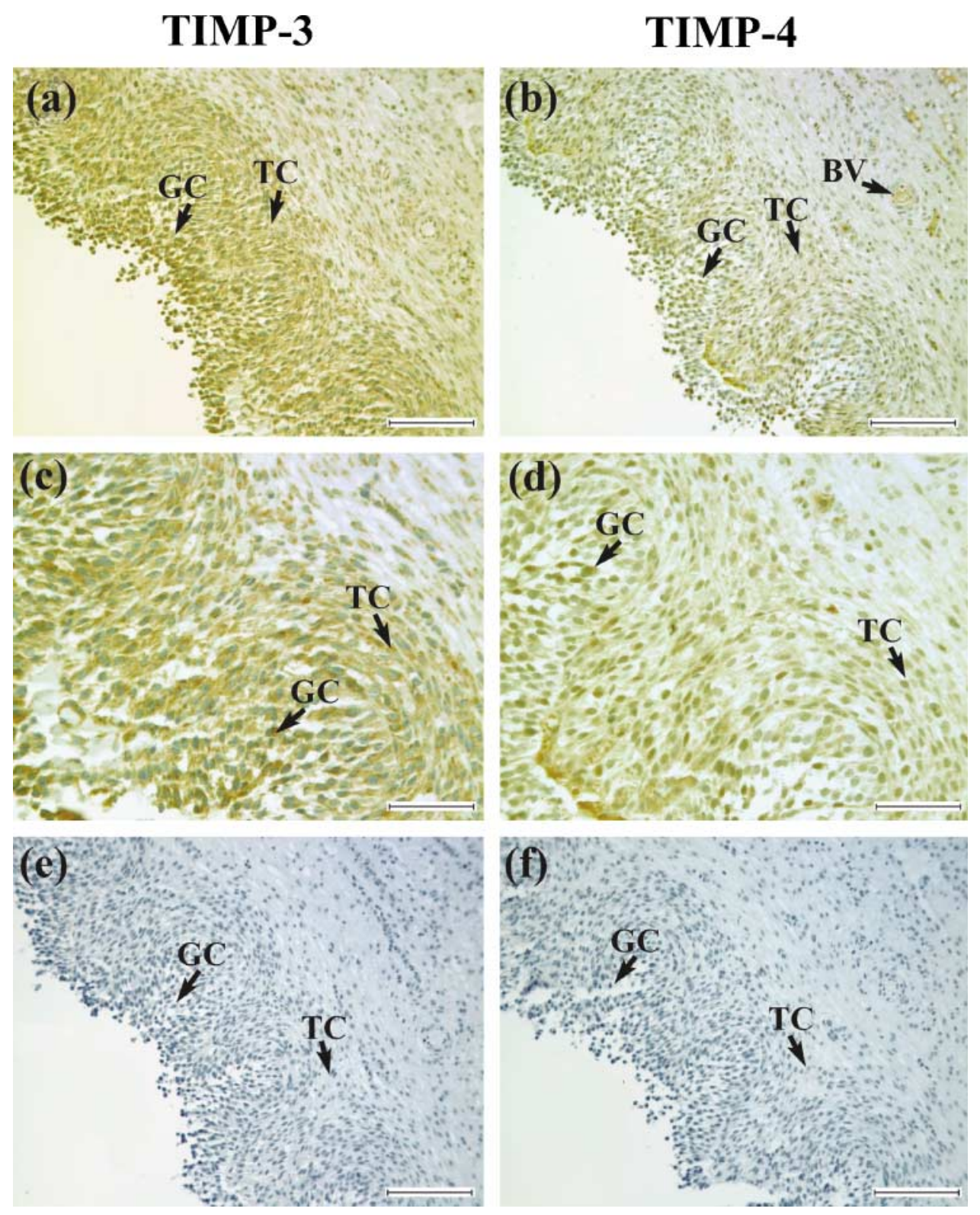